\title{
Madeira-a tourist destination for asthma sufferers
}

\author{
Irene Camacho $^{1} \cdot$ Agnieszka Grinn-Gofroń $^{2} \cdot$ Roberto Camacho $^{1} \cdot$ Pedro Berenguer $^{3}$ • \\ Magdalena Sadyśs ${ }^{4}$
}

Received: 10 November 2015 /Revised: 17 March 2016/Accepted: 22 March 2016 / Published online: 30 May 2016

(C) ISB 2016

\begin{abstract}
Madeira Island is a famous tourist destination due to its natural and climatic values. Taking into account optimal weather conditions, flora richness and access to various substrates facilitating fungal growth, we hypothesised a very high risk of elevated fungal spore and pollen grain concentrations in the air of Funchal, the capital of Madeira. Concentration levels of the most allergenic taxa were measured from 2003 to 2009, using a 7-day volumetric air sampler, followed by microscopy analysis. Dependence of bioaerosols on the weather conditions and land use were assessed using spatial and statistical tools. Obtained results were re-visited by a comparison with hospital admission data recorded at the Dr. Nélio Mendonça Hospital in Funchal. Our results showed that despite propitious climatic conditions, overall pollen grain and fungal spore concentrations in the air were very low and did not exceed any clinically established threshold values. Pollen and spore peak concentrations also did not match with asthma outbreaks in the winter. Identification of places that are "free" from biological air pollution over the summer, such as Madeira Island, is very important from the allergic point of view.
\end{abstract}

Electronic supplementary material The online version of this article (doi:10.1007/s00484-016-1163-6) contains supplementary material, which is available to authorized users.

Irene Camacho

camire@uma.pt

1 Life Science Competence Centre, Madeira University, Campus Universitário da Penteada, 9000-390 Funchal, Portugal

2 Department of Plant Taxonomy and Phytogeography, University of Szczecin, Waska 13 Street, 71-415 Szczecin, Poland

3 Centro de Química da Madeira (CQM), Madeira University, Campus Universitário da Penteada, 9000-390 Funchal, Portugal

4 Rothamsted Research, West Common, Harpenden AL5 2JQ, UK
Keywords Allergy $\cdot$ Aerobiology $\cdot$ Meteorological parameters $\cdot$ Holiday $\cdot$ Circular statistics

\section{Introduction}

The triggering of respiratory allergic diseases is often related with the occurrence of environmental bioaerosols. It is believed that the prevalence and severity of such disorders continue to increase. The changing environment and lifestyle are considered significant causes for such increase. The alarming increase in allergic disorders such as allergic rhinitis, bronchial asthma and atopic dermatitis affects more than $30 \%$ of the population worldwide (Singh and Mathur 2012).

Asthma is a chronic disease of the airways characterised by recurrent attacks of breathlessness and wheezing, which vary in severity and frequency from person to person (To et al. 2012; WHO 2015). It is one of the most common chronic diseases in the world that affects the general population. Asthma causes a considerable burden to patients often restricting their daily activities and quality of life, being also an important cause of medical emergency visits and hospitalisations (Galán et al. 2007; Héguy et al. 2008; Masoli et al. 2004; Ruffoni et al. 2013).

A recent cross-sectional world health survey of asthma burden in adults estimated that nearly 623 million individuals are currently living with some level of asthma-related symptoms (To et al. 2012). The prevalence of clinical asthma in the Portuguese population is $4.8 \%$, and the rate of mortality is $6.9 \%$ (Masoli et al. 2004). Comparatively to other countries, the prevalence of asthma in childhood in Portugal is lower than in many countries in South America or even in other former Portuguese ex-colonies (Masoli et al. 2004). In Portugal, the sensitisation prevalence to pollens is an important factor for people with rhinitis and/or rhinoconjunctivitis allergic 
aetiology. Studies of the prevalence of sensitivity to pollens using skin prick tests revealed values ranging from 10 to $70 \%$ (Loureiro et al. 2003). Most of the patients suffering from hypersensitivity to pollen rhinitis are often associated with conjunctivitis. The complaints of rhinoconjunctivitis are more prevalent in the spring, especially from April to late June.

Although the genetic predisposition is essential for the development of the allergic condition, the environment is important in triggering hypersensitivity (Nunes and Ladeira 2012). Asthma, in particular, is a heterogeneous disease caused by multiple factors, and several studies have been focused on environmental factors that may be associated with the risk of developing such disease. Air pollution, pollen levels and meteorological variables have been the most studied parameters (Brito et al. 2007; Héguy et al. 2008; Makra et al. 2015; Rosas et al. 1998).

As such, there is a growing interest in the presence and dispersion of bioaerosols in the atmosphere and their impact on human health. Particles, such as pollen grains and fungal spores, represent an important fraction of bioaerosol matter being frequently implicated in allergic symptoms. Their presence in the atmosphere is directly affected by weather conditions (Tormo-Molina et al. 2010), and for that reason, several studies have emphasised the influence of meteorological parameters on airborne pollen and fungal spore concentration and dispersion (e.g. Sadyś et al. 2015a).

Beyond the meteorological influence, the presence of these airborne particles mainly depends on the kind of vegetation growing in surrounding places, the season of the year and plant phenology (D’Amato and Liccardi 1994). In addition, pollen grains react with air pollution which in turn influences plant allergenicity (Puc and Bosiacka 2011). Understanding those correlations will help to prevent and manage allergic diseases in general. Further, detailed information on the daily and seasonal variations of bioaerosols is essential for an effective diagnosis and treatment of these ailments. A pollen distribution map throughout the Europe was described in detail in the literature, reporting the pollen of Parietaria, olive, grass and cypress as the most important ones for countries with the Mediterranean climate, taking into account both their allergenic properties and abundance in the air (D'Amato et al. 2007).

Fungal spores have also been considered as one of the causes of allergic asthma (Newson et al. 2000) and for that reason have been regularly monitored in several countries (Abu-Dieyeh et al. 2010; Ataygul et al. 2007; Dixit et al. 2000; Gonianakis et al. 2005; Sousa et al. 2015). Some studies have included the fungal spore levels as a potential confounding factor in respiratory diseases (Atkinson et al. 2006; Dales et al. 2000; Newson et al. 2000), but few have considered the influence of the geo-climatic features of each region in the development and incidence of allergic disease. Madeira is one of the most important touristic regions of Portugal. Its natural environment is the strongest asset in attracting tourists, accomplishing more than 1,010,000 tourists in 2005 (Oliveira and Pereira 2008). Madeira belongs to Madeira Archipelago, having edaphoclimatic conditions favourable to the occurrence of both pollen grains and fungal spores whose levels might affect the local population and visitors.

Taking into account these considerations, we hypothesised a very high risk of elevated fungal spore and pollen grain concentrations in the air of Funchal, the capital of Madeira. Fungal spores have been considered one of the causes of allergic asthma (Newson et al. 2000) and a risk for emergency hospital admissions, particularly in children (Atkinson et al. 2006). In view of these concerns, this study aimed to assess the influence of the prevailing environmental and aerobiological conditions in Madeira in the asthma symptoms burden.

\section{Materials and methods}

\section{Site location, land use cover and climate}

Madeira Archipelago is a volcanic group of islands located in the Atlantic Ocean about $500 \mathrm{~km}$ north of Canary Archipelago and southwest of Portugal (Fig. 1). With $737 \mathrm{~km}^{2}$ and about 240,000 people, Madeira is the biggest and the main island of the Archipelago. Funchal is the main town of Madeira, and the most populous insular city of the mainland (Portugal).

Madeira has a climate influenced by the subtropical anticyclone of the Azores, with a temperate hyperoceanic subMediterranean bioclimate influence. By this reason and geographical location, Madeira has a subtropical climate with Funchal within the thermo-sub-Mediterranean and thermoMediterranean thermo-climatic belts (Rivas-Martínez 2001). Relative humidity varies between 55 and $75 \%$, rainfall between 500 and $1000 \mathrm{~mm}$ and temperature between $15.9^{\circ} \mathrm{C}$ in February and $22.3{ }^{\circ} \mathrm{C}$ in August with an annual average of $18.7{ }^{\circ} \mathrm{C}$ (Quintal 2007). The predominant wind direction varies from the South-West quadrant during the winter to the North quadrant during the summer (Santos et al. 2004).

The main island is constituted in about two thirds of a natural park that includes the Laurel forest, locally called Laurissilva, a UNESCO world heritage site being one of the best-preserved forests of Macaronesia (Fig. 1). Gardens and parks of Funchal have a variety of exotic plants (e.g. Cupressaceae, Casuarina and tree ferns). Exotic species such as genera Acacia, Eucalyptus and Pinus can be found surrounding Funchal. In urban areas, land for agriculture purposes (e.g. banana-Musa acuminata and wine grapes-Vitis vinifera) can also be found that makes a typical landscape of Funchal and a potential substrate for fungal growth and reproduction.

A detailed analysis of the land use at Madeira was performed using Global Land Cover 2000 (GLC2000) dataset (EC 2003) and a combination of tools available in ArcMap (v. 10.0) software. 


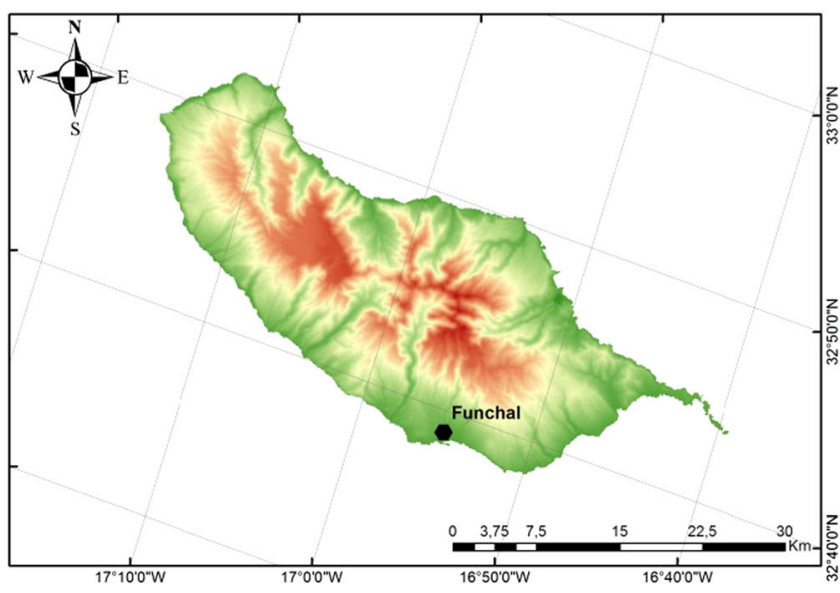

Fig. 1 The maps show an elevation of Madeira Island (http://srtm.csi. cgiar.org) with a location of sampling site (left) and land use (right) based on the Global Land Cover 2000 (EC 2003). The following classes were found: (1) mosaic - cropland, tree cover, and other natural vegetation (light yellow); (2) tree cover, broadleaved, deciduous, open (dark green)

\section{Spore and pollen sampling}

The airborne spore and pollen monitoring was performed with a Burkard 7-day volumetric trap (Hirst type), from Jan. 2003 to Dec. 2009, following the guidelines of the International Association for Aerobiology and the recommendations proposed by the Spanish Aerobiology Network (Galán et al. 2007). The air sampler was placed on the roof of Dr. João Almada Hospital in Funchal, $10 \mathrm{~m}$ above the ground $\left(32^{\circ}\right.$ $\left.39^{\prime} \mathrm{N}, 16^{\circ} 55^{\prime} \mathrm{W}\right)$. The identification and counting of spores and pollen grains were performed with a light microscope $(\times 400)$, based on four longitudinal transects along the slides that resulted in scanning $13 \%$ of the microscope slide.

Spore (Alternaria, Cladosporium) and pollen (Betulaceae, Olea, Poaceae, Urticaceae) counts were converted into atmospheric concentrations and expressed as the number of spores $\left[\mathrm{s} \mathrm{m}^{-3}\right]$ or pollen grains $\left[\mathrm{g} \mathrm{m}^{-3}\right]$ per cubic metre of air. In order to verify the accuracy of calculations performed under the microscope, most of the samples were reviewed using a digital camera connected to a computer screen. The calculations presented in this study were made based on the daily mean concentration of the airborne particles and the daily mean values of the weather parameters that were available, i.e. maximum, minimum and mean temperature; relative humidity; precipitation; and wind direction. Meteorological data were provided by the Portuguese Sea and Atmosphere Institute (IPMA), Funchal, and covered the period from Jan. 2003 to Dec. 2009.

\section{Emergency visits}

The database containing patient history was produced since Jun. 2005, and therefore, only the period overlapping with the spore and pollen measurements was selected for a detailed examination (Jun. 2005-Dec. 2009). Initially, patients who

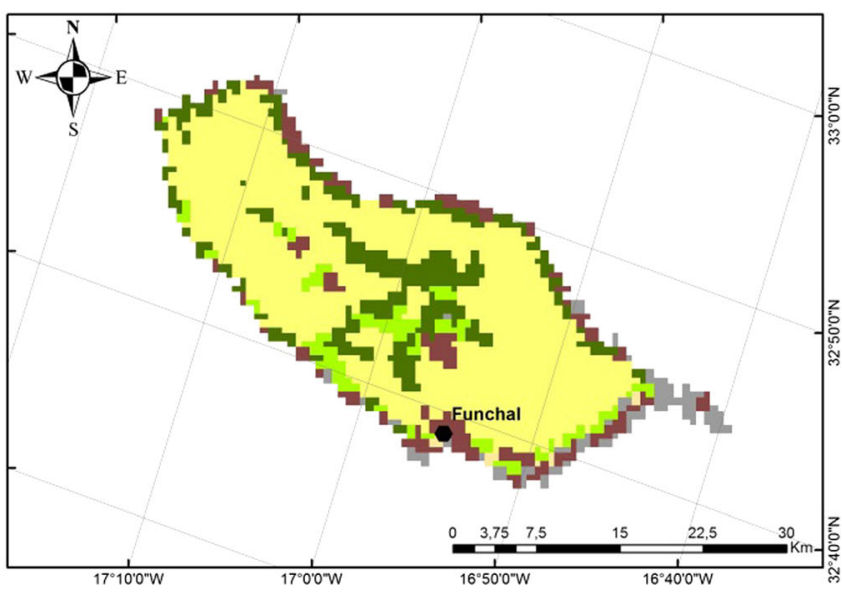

; (3) shrub cover, closed-open, evergreen (light green); (4) bare areas (dark brown); (5) sparse herbaceous or sparse shrub cover (dark grey); and (6) herbaceous cover, closed-open (beige). More details regarding each land use class can be found at http://www.fao.org/docrep/003/ X0596E/x0596e01f.htm\#p381_40252

reported symptoms similar to asthma during the registration at the emergency room (ER) were selected. This group was then narrowed down to patients who were located either at pneumology, ENT (eyes, nose, throat), paediatrics, special care unit and multipurpose intensive care unit departments; who were sent back home; or who have died during the visit at the hospital. All patients were then divided into three age groups, i.e. children ( $0-15$ years), adults (16-59 years) and seniors (60-98 years) after Rosas et al. (1998).

\section{Statistical testing}

Seasonality of bioaerosol occurrence at Funchal was assessed by calculating $90 \%$ (spore) and $95 \%$ (pollen) accumulative daily mean concentration following Nilsson and Persson (1981). Upon the preliminary pollen, spore, weather and asthma admission rates through data screening with the aid of descriptive statistics, Shapiro-Wilk test and matrix scatter plots, it was necessary to apply non-parametric statistics for further testing. All dependencies, i.e. (1) pollen and spore concentration vs. weather, (2) number of emergency visits vs. pollen and spore concentration, and (3) number of emergency visits vs. meteorological parameters were examined using Spearman's rank test, while annual variations in bioaerosol occurrence in the air and hospital admission rates were studied using ANOVA Kruskal-Wallis test. All calculations were performed in GenStat (v. 17) software.

In addition to above, circular statistics was applied since measurements of the local wind distribution represent a directional type of data (Aradóttir et al. 1997; Kasprzyk 2008). Initial data screening was limited to descriptive statistical tools, such as mean direction, circular standard deviation, mean resultant length, skewness, kappa estimate, probability test of randomness, probability Rayleigh test of uniformity, 
chi-square von Mises and probability chi-square von Mises, all available in "cdescribe" package of the GenStat (v.17) software (Fisher 1993). Subsequently, the annual variations in local wind direction were investigated using "ccompare" module containing tests for comparing circular distributions, test for a common mean direction and test of homogeneity, which jointly constitute an equivalent for the ANOVA Kruskal-Wallis test for circular data (Fisher 1993). The "cassociation" module (Fisher 1993), which includes tests for linear-circular association, was then used in order to study the relationship between local wind direction and bioaerosol distribution.

\section{Results}

\section{Land use analysis}

An analysis of the Madeira land use showed that the biggest territory of the island was occupied by a mosaic consisted of croplands, trees and other natural vegetation $(62.93 \%)$, while the second most dominant land use class turned out to be forest areas made of broadleaved, deciduous and open trees $15.82 \%$ (Table 1, Fig. 1).

\section{Bioaerosol levels and their dependence on the weather}

Overall, concentrations of all examined fungal spore and pollen grain genera, in the air of Funchal were very low (Table 2). Results of ANOVA Kruskal-Wallis test showed that there was a statistically significant difference $(p<0.001)$ in annual distributions of spores, i.e. Alternaria $(H=29.78)$ and Cladosporium $(H=74.56)$, as well as pollen, i.e. Betulaceae $(H=22.72)$, Olea $(H=9.88)$, Poaceae $(H=41.56)$ and Urticaceae $(H=77.34)$. The Spearman's correlation coefficient value between both studied spore types was equal to $r_{s}=0.446(p<0.001)$.

Table 1 Land use statistics for Madeira island based on the GLC2000 dataset

\begin{tabular}{llll}
\hline Land cover class & Class no. & Area (ha) & Area (\%) \\
\hline $\begin{array}{l}\text { Tree cover, broadleaved, deciduous, } \\
\quad \text { open }\end{array}$ & 3 & 2071 & 15.82 \\
$\begin{array}{l}\text { Shrub cover, closed-open, deciduous } \\
\text { Herbaceous cover, closed-open }\end{array}$ & 12 & 831 & 6.35 \\
$\begin{array}{l}\text { Sparse herbaceous or sparse shrub } \\
\quad \text { cover }\end{array}$ & 14 & 71 & 0.54 \\
$\begin{array}{l}\text { Cropland/tree cover/other natural } \\
\quad \text { vegetation }\end{array}$ & 17 & 8236 & 4.90 \\
$\begin{array}{l}\text { Bare areas } \\
\text { Total }\end{array}$ & 19 & 1238 & 9.46 \\
\hline
\end{tabular}

The length of fungal spore seasons ranged from 199 to 321 days (Alternaria) and from 203 to 319 days (Cladosporium) (Table 2). Cladosporium spores were mainly present in the air between January and November while Alternaria from February to November. Commonly accepted threshold values for triggering the asthma attacks at sensitised individuals, i.e. $100 \mathrm{~s} \mathrm{~m}^{-3}$ for Alternaria and $3000 \mathrm{~s} \mathrm{~m}^{-3}$ for Cladosporium (Table 3), within 7 years of study were not exceeded at all. The maximum concentration of Alternaria spores was observed on 14 Nov. $2009\left(60 \mathrm{~s} \mathrm{~m}^{-3}\right)$ while Cladosporium spores peaked on 8 Oct. 2009 reaching $217 \mathrm{~s} \mathrm{~m}^{-3}$ (Table 2).

Regarding the pollen grain genera, the pollen seasons usually began in February-March and lasted till OctoberNovember (Table 2). In general, Olea showed the shortest pollen season (lasted on average 205 days), while Urticaceae pollen seasons revealed the longest seasons (on average 215 days). The first pollen peak concentrations appeared with Urticaceae in March. Then, Betulaceae pollen prevailed between April and May, along with Urticaceae. The pollen of Poaceae reached peaks intermittently, revealing maximum concentration in April and June.

The maximum Urticaceae pollen concentrations were observed in 2008 and 2009 on 7 April $\left(45 \mathrm{~g} \mathrm{~m}^{-3}\right)$ and on 28 March $\left(44 \mathrm{~g} \mathrm{~m}^{-3}\right)$, respectively (Table 2). The second highest maximum pollen concentrations were found for Betulaceae on 10 April $2009\left(31 \mathrm{~g} \mathrm{~m}^{-3}\right)$. Similarly, a clinically established threshold value of $35 \mathrm{~g} \mathrm{~m}^{-3}$ for grass pollen in Spain was never exceeded (Tables 2 and 3 ).

The presence of spores in the air was not directly dependent on the changes of the weather conditions (Table 4). The correlation coefficient values of the statistically significant relationships between Alternaria and meteorological parameters was 0.072-0.075 ( $p \leq 0.05$ ), while for Cladosporium -0.074 $0.095(p \leq 0.05)$. In both cases, the most influencing factor was found to be temperature while for Cladosporium, an equally important factor was also rainfall. Furthermore, the correlation analysis showed statistically significant values $(p \leq 0.05)$ between most pollen types and meteorological parameters (Table 4). The strongest correlation coefficient value between meteorological parameters and Betulaceae was -0.040 , for Poaceae, it was varying from -0.047 to $0.039(p \leq 0.05)$, whereas for Urticaceae, it ranged between -0.066 and $-0.049(p \leq 0.05)$.

\section{Emergency visits and their associations with weather and bioaerosols}

In the analysed period of time (Jun. 2005-Dec. 2009), 5143 patients with asthma symptoms were admitted to the hospital, what constituted merely $3.04 \%$ of the total number of registered patients in the emergency room at that time (Table 5, 
Table 2 Characteristics of fungal spore and pollen grain seasons at Funchal, Madeira (Jan. 2003-Dec. 2009)

\begin{tabular}{|c|c|c|c|c|c|c|c|c|}
\hline & Year & 2003 & $2004^{\mathrm{a}}$ & 2005 & 2006 & 2007 & $2008^{\mathrm{a}}$ & 2009 \\
\hline \multirow[t]{6}{*}{ Alternaria } & Start of season & 25 Apr. & 26 Feb. & 12 Jan. & 9 Mar. & 1 Mar. & $27 \mathrm{Feb}$ & $11 \mathrm{Feb}$. \\
\hline & End of season & 18 Nov. & 11 Sep. & 28 Nov. & 18 Nov. & 19 Dec. & 8 Dec. & 14 Nov. \\
\hline & Duration $[n$ days] & 208 & 199 & 321 & 255 & 294 & 286 & 277 \\
\hline & Peak value & 8 & 23 & 8 & 5 & 42 & 30 & 60 \\
\hline & Date of peak & 27 Apr. & 25 Mar. & 16 Apr. & 7 Aug. & $15 \mathrm{Jul}$. & 27 Apr. & 14 Nov. \\
\hline & SFI & 117 & 113 & 97 & 39 & 370 & 165 & 395 \\
\hline \multirow[t]{6}{*}{ Cladosporium } & Start of season & 25 Apr. & 13 Jan. & 8 Feb. & 27 Apr. & 19 Jan. & 28 Jan. & 19 Jan. \\
\hline & End of season & 17 Nov. & 19 Sep. & 22 Nov. & 15 Nov. & 3 Dec. & 22 Nov. & 11 Nov. \\
\hline & Duration $[n$ days] & 207 & 251 & 288 & 203 & 319 & 300 & 297 \\
\hline & Peak value & 190 & 43 & 117 & 122 & 104 & 183 & 217 \\
\hline & Date of peak & 26 Apr. & 10 Mar. & 11 Apr. & 24 Jul. & 28 Mar. & 23 Apr. & 8 Oct. \\
\hline & SFI & 3829 & 1171 & 1821 & 1727 & 2270 & 2896 & 2155 \\
\hline \multirow[t]{6}{*}{ Betulaceae } & Start of season & 2 May & $5 \mathrm{Feb}$. & 5 Feb. & 31 Mar. & 5 Feb. & 9 Mar. & 12 Mar. \\
\hline & End of season & 30 Nov. & 22 Oct. & 15 Oct. & $1 \mathrm{Jul}$. & 19 Aug. & 26 Nov. & 4 Oct. \\
\hline & Duration [ $n$ days] & 213 & 261 & 253 & 93 & 196 & 263 & 207 \\
\hline & Peak value & 5 & 2 & 3 & 8 & 4 & 18 & 31 \\
\hline & Date of peak & 8 May & 7 Apr. & 27 Apr. & 9 May & 13 Jun. & 14 May & 10 Apr. \\
\hline & SPI & 56 & 30 & 24 & 78 & 42 & 121 & 511 \\
\hline \multirow[t]{6}{*}{ Olea } & Start of season & - & 11 Jan. & 11 Jan. & 6 Mar. & 17 May & 11 Jan. & 4 Mar. \\
\hline & End of season & - & 17 Jun. & 17 Jun. & 6 Nov. & 26 Sep. & 21 Oct. & 6 Nov. \\
\hline & Duration [ $n$ days] & - & 159 & 158 & 246 & 133 & 285 & 248 \\
\hline & Peak value & - & 2 & 2 & 3 & 2 & 1 & 14 \\
\hline & Date of peak & - & 22 May & 22 May & 21 Jun. & 17 May & $\begin{array}{l}11 \text { Jan. } \\
21 \text { Oct. }\end{array}$ & 07 Oct. \\
\hline & SPI & 0 & 7 & 6 & 11 & 7 & 2 & 82 \\
\hline \multirow[t]{6}{*}{ Poaceae } & Start of season & 9 Jan. & 11 Jan. & 11 Jan. & 6 May & 12 Feb. & 5 Apr. & 16 Mar. \\
\hline & End of season & 18 Dec. & 12 Nov. & 29 Nov. & 2 Nov. & 27 Dec. & 7 Nov. & 9 Nov. \\
\hline & Duration [ $n$ days] & 343 & 307 & 323 & 181 & 319 & 217 & 239 \\
\hline & Peak value & 5 & 9 & 9 & 39 & 9 & 31 & 28 \\
\hline & Date of peak & 30 Jun. & 25 Jun. & 25 Jun. & 1 Sep. & 28 Jun. & 5 Apr. & 4 Apr. \\
\hline & SPI & 46 & 53 & 53 & 347 & 84 & 231 & 558 \\
\hline \multirow[t]{6}{*}{ Urticaceae } & Start of season & 24 Apr. & 21 Jan. & 23 Jan. & 10 Mar. & 27 Jan. & 4 Mar. & 15 Jan. \\
\hline & End of season & 3 Aug. & $10 \mathrm{Jul}$. & 19 Nov. & 2 Aug. & 28 Nov. & 27 Aug. & 10 Nov. \\
\hline & Duration [ $n$ days] & 102 & 172 & 301 & 146 & 306 & 177 & 300 \\
\hline & Peak value & 12 & 6 & 8 & 33 & 24 & 45 & 44 \\
\hline & Date of peak & 24 Apr. & 27 May & 21 Apr. & 10 Mar. & 4 Mar. & 7 Apr. & 28 Mar. \\
\hline & SPI & 158 & 171 & 237 & 225 & 159 & 361 & 828 \\
\hline
\end{tabular}

SFI Seasonal Fungal Index (sum of the daily mean spore concentration within a season), SPI Seasonal Pollen Index (sum of the daily mean pollen grain concentration within a season)

${ }^{\mathrm{a}}$ Leap year

Fig. 2). Results of ANOVA Kruskal-Wallis test showed that there was a statistically significant difference in annual distributions of a number of patients admitted to the hospital with symptoms related to asthma, regardless whether year 2005 was included $(H=32.74, p<0.001)$ or not $(H=10.81$, $p<0.01)$. The greatest number of cases was found in adults group $(49.19 \%)$ and the lowest at children $(16.92 \%)$. Seven death cases caused by asthma were found during analysed period of time, and this concerned three women and four men (Fig. 2).

In relation to the sex and age of all admitted patients, then women at the age between 16 and 59 years old were more frequently exhibiting asthma symptoms comparing to men while this situation was reversed as men were found to be more susceptible at child age and senior age. However, overall there was not much difference between the gender ratio of all 
Table 3 Concentration levels of bioaerosol that trigger symptoms of asthma

\begin{tabular}{llll}
\hline Bioaerosol & Threshold $^{\text {a }}$ & Country & References \\
\hline Alternaria & 50 & UK & Frankland and Davies (1965) \\
& 80 & Poland & Rapiejko et al. (2007) \\
& 100 & Finland & Ranta and Pessi (2006) \\
Cladosporium & 2800 & Poland & Rapiejko et al. (2007) \\
& 3000 & UK & Frankland and Davies (1965) \\
& 4000 & Finland & Ranta and Pessi (2006) \\
Betulaceae & 70 & France & Caillaud et al. (2014) \\
& 75 & Poland & Rapiejko et al. (2007) \\
Olea & 162 & Spain & Brito et al. (2011) \\
& 400 & Spain & Florido et al. (1999) \\
Poaceae & 35 & Spain & Brito et al. (2010) \\
& 50 & Poland & Rapiejko et al. (2007) \\
& 50 & Sweden & Kiotseridis et al. (2013) \\
Urticaceae & 80 & Italy & Negrini et al. (1992) \\
\hline
\end{tabular}

${ }^{a}$ Expressed as number of fungal spores or pollen grains per cubic metre of air

registered patients, as women and men showed almost identical morbidity ratio (51:49).

A maximum daily number of emergency visits varied between six patients (at children group) and eight patients (at adults group). On average, the greatest number of patients with asthma-related symptoms were registered during the winter period, i.e. in November (children, $n=26$ ), in December (adults, $n=54$ ) and in February (seniors, $n=44$ ), (Fig. 3).

Figures 4, 5, and 6 show the annual distribution of the number of emergency visits together with annual changes in the total sum of daily mean pollen and spore concentrations plotted against the annual mean air temperature, annual mean relative humidity and annual sum of rainfall. These dependencies were then further examined using Spearman's rank test, which showed that a number of hospital admissions related to asthma symptoms were positively correlated with the presence of rainfall and negatively correlated with air temperature (Table 4). None of the relationships between a number of emergency visits and pollen and spore concentrations (Table 6) was found to be statistically significant $(p \leq 0.05)$.

\section{Wind direction analysis}

Table S1 shows results of the descriptive circular statistics performed for the local wind direction that was measured at Funchal, Madeira (Jan. 2003-Dec. 2009). The annual mean wind direction remained constant throughout the period of the first 6 years and oscillated from the SW to SE bearing (Fig. S1). In 2009, the final year under investigation, the mean wind direction was found to originate from the NNE direction (Fig. S1). This discrepancy in annual wind direction pattern was also confirmed by the Rayleigh's test of uniformity (Table S1). Similar findings were obtained by looking at other circular parameters, for example, the circular dispersion; in years 2003-2008, the circular dispersion was found to be $<27^{\circ}$, while in 2009 , this value rose to $113^{\circ}$, thus it was $>4$ times higher than in the previous years.

\section{Discussion and conclusion}

The knowledge of the potentially allergenic pollen and spore counts and their changes throughout the year in a given area is of great importance for allergic persons and for the determination of the origins of the disease and recommendation of an effective therapy. The production and distribution of such bioaerosols are highly influenced by weather phenomena.

Taking into account the climatic conditions and land use of Madeira Island (Table 1, Fig. S2), we hypothesised very high levels of both fungal spores (Alternaria, Cladosporium) and pollen grains (Betulaceae, Olea, Poaceae, Urticaceae) in the air of Funchal. However, the overall concentration levels of all selected bioaerosols throughout the period under investigation
Table 4 Results of Spearman's rank correlation test between environmental factors and daily number of emergency visits and bioaerosol concentrations measured at Funchal, Madeira (2003-2009)

\begin{tabular}{lllllll}
\hline Bioaerosol & TMAX & TMIN & TME & RAIN & RH & WIND $^{\text {a }}$ \\
\hline Alternaria & $0.075^{*}$ & $0.072^{*}$ & $0.075^{*}$ & -0.015 & 0.033 & 0.000 \\
Cladosporium & $0.088^{*}$ & $0.084^{*}$ & $0.095^{*}$ & $-0.074^{*}$ & 0.031 & 0.002 \\
Betulaceae & -0.033 & -0.030 & -0.020 & $-0.040^{*}$ & -0.022 & 0.000 \\
Olea & 0.008 & 0.009 & 0.011 & 0.018 & 0.038 & 0.000 \\
Poaceae & $0.173^{*}$ & $0.187^{*}$ & $0.190^{*}$ & $-0.047^{*}$ & $0.039^{*}$ & 0.000 \\
Urticaceae & $-0.060^{*}$ & $-0.066^{*}$ & $-0.049^{*}$ & -0.034 & 0.022 & 0.000 \\
Emergency visits & $-0.106^{*}$ & $-0.093^{*}$ & $-0.100^{*}$ & $0.015^{*}$ & -0.028 & 0.000 \\
\hline
\end{tabular}

Abbreviations: TMAX maximum temperature $\left({ }^{\circ} \mathrm{C}\right), T M I N$ minimum temperature $\left({ }^{\circ} \mathrm{C}\right), T M E$ mean temperature $\left({ }^{\circ} \mathrm{C}\right)$, RAIN rainfall $(\mathrm{mm}), R H$ relative humidity $(\%), W I N D$ wind direction $\left({ }^{\circ}\right)$

* Statistical significance at $p \leq 0.05$

${ }^{\text {a }}$ Circular association test was used 
Table 5 Asthma attacks at different age groups of patients at Funchal, Madeira (Jun. 2005-Dec. 2009)

\begin{tabular}{lllllllll}
\hline Group & Year & $\begin{array}{l}\text { Total number } \\
\text { of cases }\end{array}$ & F & M & $A_{F}$ & $M_{F}$ & $A_{M}$ & $M_{M}$ \\
\hline Children (0-15 years) & 2005 & 89 & 29 & 60 & 8 & 9 & 8 & 9 \\
& 2006 & 220 & 79 & 141 & 8 & 6 & 7 & 7 \\
& 2007 & 212 & 77 & 135 & 8 & 7 & 8 & 7 \\
& 2008 & 181 & 64 & 117 & 9 & 8 & 8 & 8 \\
& 2009 & 168 & 70 & 98 & 8 & 8 & 8 & 8 \\
Adults (16-59 years) & 2005 & 235 & 154 & 81 & 38 & 39 & 39 & 41 \\
& 2006 & 574 & 390 & 184 & 39 & 41 & 40 & 42 \\
& 2007 & 595 & 345 & 250 & 40 & 41 & 39 & 38 \\
& 2008 & 563 & 330 & 233 & 40 & 42 & 38 & 40 \\
Seniors (60-98 years) & 2009 & 563 & 287 & 276 & 38 & 38 & 39 & 43 \\
& 2005 & 171 & 63 & 108 & 71 & 70 & 71 & 70 \\
& 2006 & 447 & 198 & 249 & 74 & 73 & 73 & 72 \\
& 2007 & 405 & 187 & 218 & 73 & 73 & 72 & 72 \\
& 2008 & 361 & 164 & 197 & 72 & 72 & 72 & 72 \\
& 2009 & 359 & 176 & 183 & 71 & 70 & 71 & 71 \\
\hline
\end{tabular}

Abbreviations: $F$ female, $M$ male, $A_{F}$ female average age, $M_{F}$ female median age, $A_{M}$ male average age, $M_{M}$ male median age

were found to be very low (Table 2), and therefore, we had to reject this hypothesis. None of them exceeded the threshold values established clinically by several independent research groups (Table 3), nor was statistically significantly correlated with a number of patients admitted to the hospital (Table 6). Given the timing when aeroallergens were present in the air of sampling site (Table 2), as well as an increased frequency of the hospital admissions during the winter period (Figs. 2 and 3 ), it must be concluded that analysed aeroallergens were not responsible for triggering the asthma attacks. Asthma is a multifactorial disease, and for that reason, other factors beyond outdoor allergens, such as viral infections and exposure to house dust mites, can cause asthma exacerbation and subsequent hospital admissions (Ghosh et al. 2012; Global Initiative for Asthma 2010; Hodder et al. 2010). Furthermore, it was shown that a cold and dry weather in autumn corresponded to increased asthma admissions and peak days in admissions, in particularly at school-aged population, whereas hot and dry weather in summer corresponded

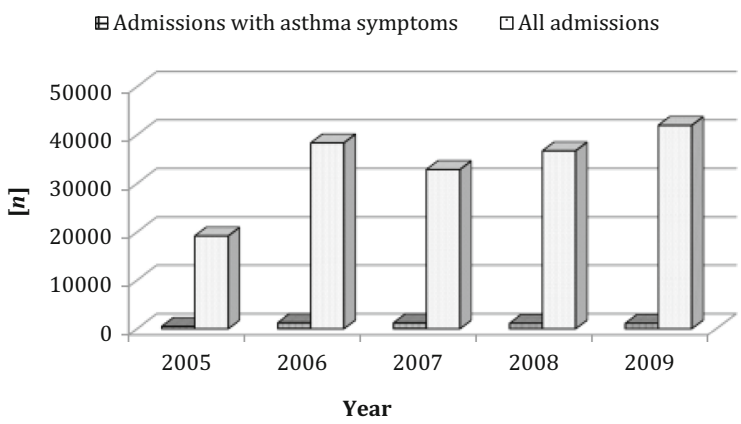

to peak days in asthma admissions (Lee et al. 2012). Other reports focusing on the relationship between weather and asthma revealed that increase in the asthma-related symptoms, as well as the need for hospital admission, was associated with dropping temperatures (May et al. 2011; D'Amato et al. 2015; Royé et al. 2015). Breathing cold air can trigger bronchoconstriction in asthmatics because physiological mechanisms linked to the cooling of the airways can trigger asthma symptoms (Koskela 2007; D'Amato et al. 2015). These reports are in agreement with our findings presented in Table 4.

Other studies conducted in countries with a similar climate showed from at least twofold higher levels of pollen such as Parietaria, which is one of the most important taxon of the Urticaceae family (Negrini et al. 1992), to 18-33-fold higher for Olea pollen (Tosunoglu and Bicakci 2015). These plants are found only in specific regions: Parietaria and olive trees are found mainly in the Mediterranean area. In turn, ragweed grows predominantly in North America, birch occurs mainly

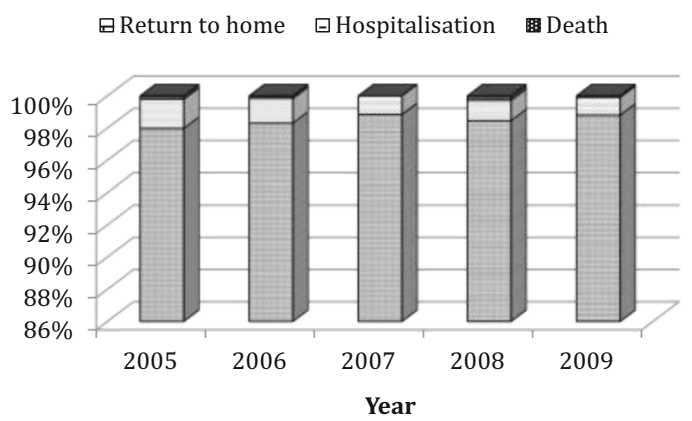

Fig. 2 Relation between the total number of hospital admissions and emergency visits with asthma symptoms (left) and further consequences of the latter group (right) recorded at Funchal, Madeira (Jun. 2005-Dec. 2009) 
Fig. 3 Mean monthly sums of the emergency visits of patients with asthma-related symptoms (top) and actual numbers of the emergency visits recorded at Funchal, Madeira between Jun. 2005 and Dec. 2009 (bottom)
Children $\square$ Adults $\square$ Seniors
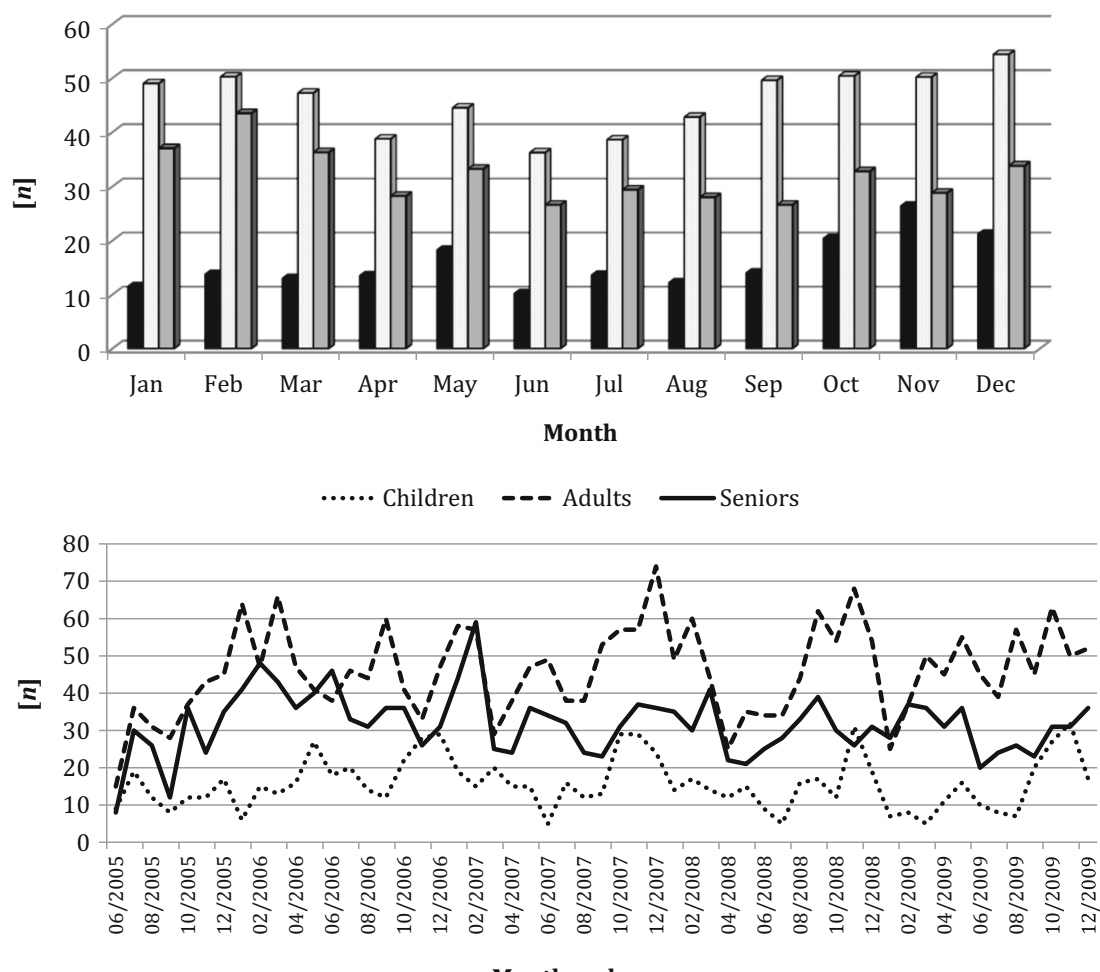

Month and year in the NW Europe (Emberlin et al. 2002) and the Japanese cedar is restricted to Japan (D'Amato 2007). Despite the occurrence of some of these allergenic taxa in Madeira Island, their concentration levels in the atmosphere are considered as low (Camacho 2015). Poaceae pollen also occurs in Madeira, which is considered as an important causal agent of asthma in Europe and a dominant element in the herbaceous vegetation of the Mediterranean landscape (Rodríguez-Rajo et al. 2010). Grasses are both annual and perennial herbs and most species are anemophilous (León-Ruiz et al. 2010) producing large amounts of pollen grains during a short period of time (Knox et al. 1993). Beyond these features, Poaceae pollen season is quite long; however, this pollen type occurs in the atmosphere of Madeira in low levels (Table 2).

In contrast, the spore counts of Alternaria and Cladosporium recorded at Funchal were similar to those reported for the Trent region (Newson et al. 2000). However, the annual average of Alternaria (185.30) and Cladosporium (2266.92) in the atmosphere of Funchal is easily surpassed by fungal spore counts detected in Thessaloniki (Greece) (Gioulekas et al. 2004) or in Madrid (Spain), where the monthly concentrations were always above $3000 \mathrm{~s} \mathrm{~m}^{-3}$ during every month of the year (Sabariego et al. 2007). The coastal proximity of Funchal city, as well as the insular condition of Madeira, might explain the low fungal spore levels, a phenomenon also observed in other regions (Aira et al. 2008; Belmonte et al. 2008). In fact, the geographical position of a given region along with the meteorological elements is an important factor that drives bioaerosol dispersal (Veriankaite et al. 2010).

In Fig. 2, annual fluctuations in hospital admission numbers were presented. In Jun. 2005, the patient database was created, and therefore, this particular year represented only 6month observation in contrast to the following years. Hence, the real lowest number of registered patients exhibiting asthma symptoms occurred in 2009, and it was equal to $n=1090$ (Fig. 2). The highest number of admitted patients with signs of asthma was found in 2006. The data did not show a visible upward or downward trend with regard to the overall number of emergency visits while specifically admissions in relation to the asthma outbreaks showed a gradual decrease of $14 \%$ from 2006 to 2009. Similar results were reported by the Global Asthma Network (2014) for Portugal, where 2000 2004 data was compared with 2008-2012. In contrast to Portugal, in many European countries, like Netherlands, Croatia, Germany or Lithuania, it has been observed a significant increase in hospital admission rates between 2008 and 2012 (Global Asthma Network (2014). Other countries of a Mediterranean climate also exhibited a decrease in numbers of registered asthma sufferers. In such type of surveys, special attention has been given to the child population. The rates of asthma attacks involving children are normally higher than in the adults (Atkinson et al. 2006; Dales et al. 2000; Galán et al. 2003). Nevertheless, in Madeira, during the period of study, a 

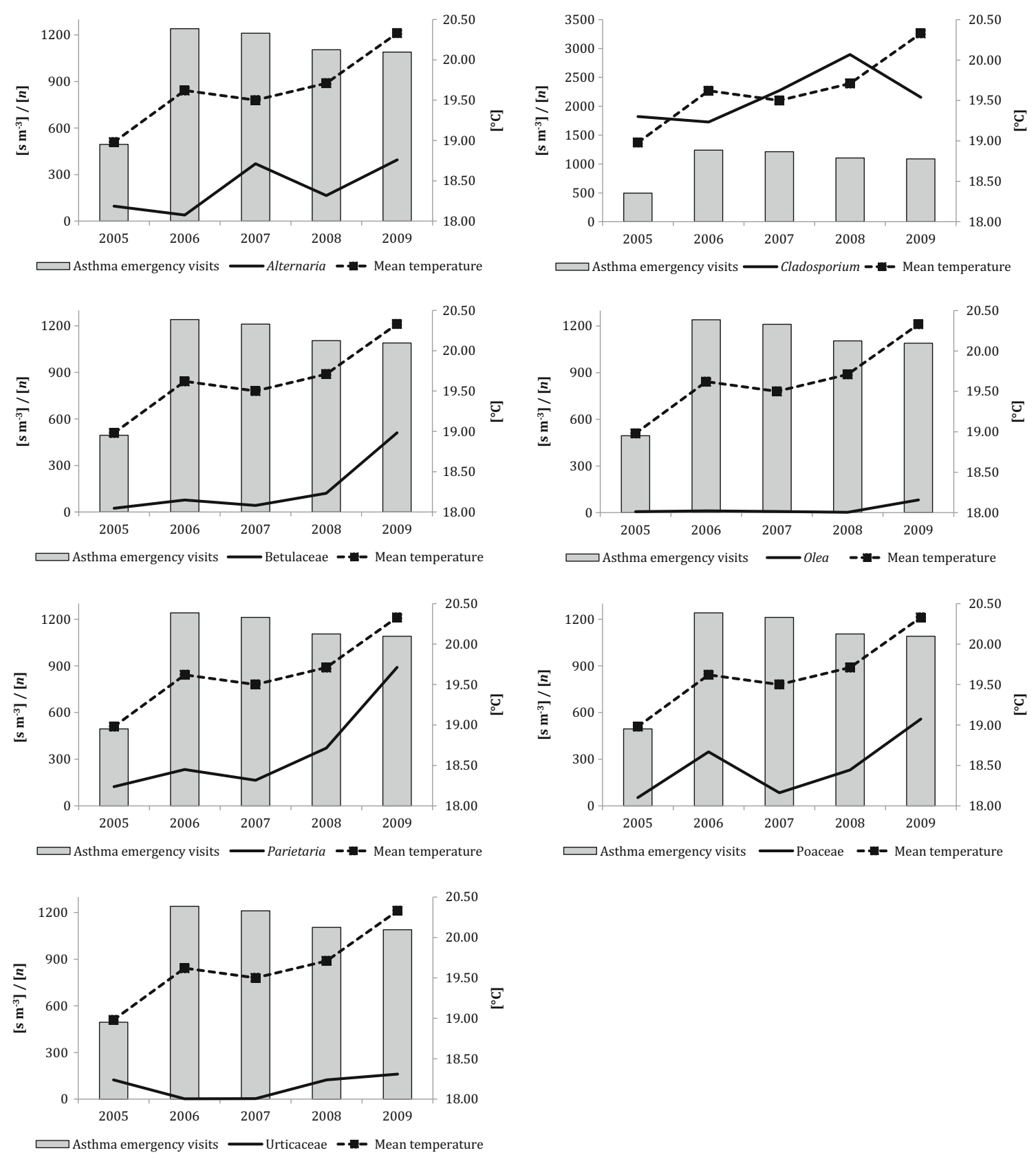

Fig. 4 Associations between examined fungal spores (Seasonal Fungal Indices) and pollen grains (Seasonal Pollen Indices), annual mean air temperature and number of asthma-related emergency visits recorded at Funchal, Madeira Island (Jun. 2005-Dec 2009)

maximum daily number of emergency visits of six children and eight adults were reported contrasting with rates ranging from 0 to 36 visits per day, $8.8 \%$ of which caused by fungal spores (Dales et al. 2000).

Another common feature is the seasonal pattern in the number of asthma events. In a survey conducted by Leblanc et al. (2013) in an emergency hospital department at Lisbon (Portugal), it was shown that months with the highest visits of asthmatic patients occurred at the end of spring time. The authors explained that some exacerbations episodes could be due to exposure to environmental allergens, as in the case of patients sensitised to pollens. A similar scenario was observed in Porto city (Ribeiro et al. 2009) where tree pollen and hospital admissions for asthma or dyspnea were positively correlated. In the particular case of our survey, we have not found an association between daily emergency visits from asthma and the periods when pollen or fungal spore allergens prevailed in the atmosphere. Further, we did not observe a periodical pattern in asthma hospital admissions, suggesting that the onset of asthma symptoms could be linked to other variables, namely the genetic background and lifestyle of the population, as suggested by Rosado-Pinto et al. (2006). 

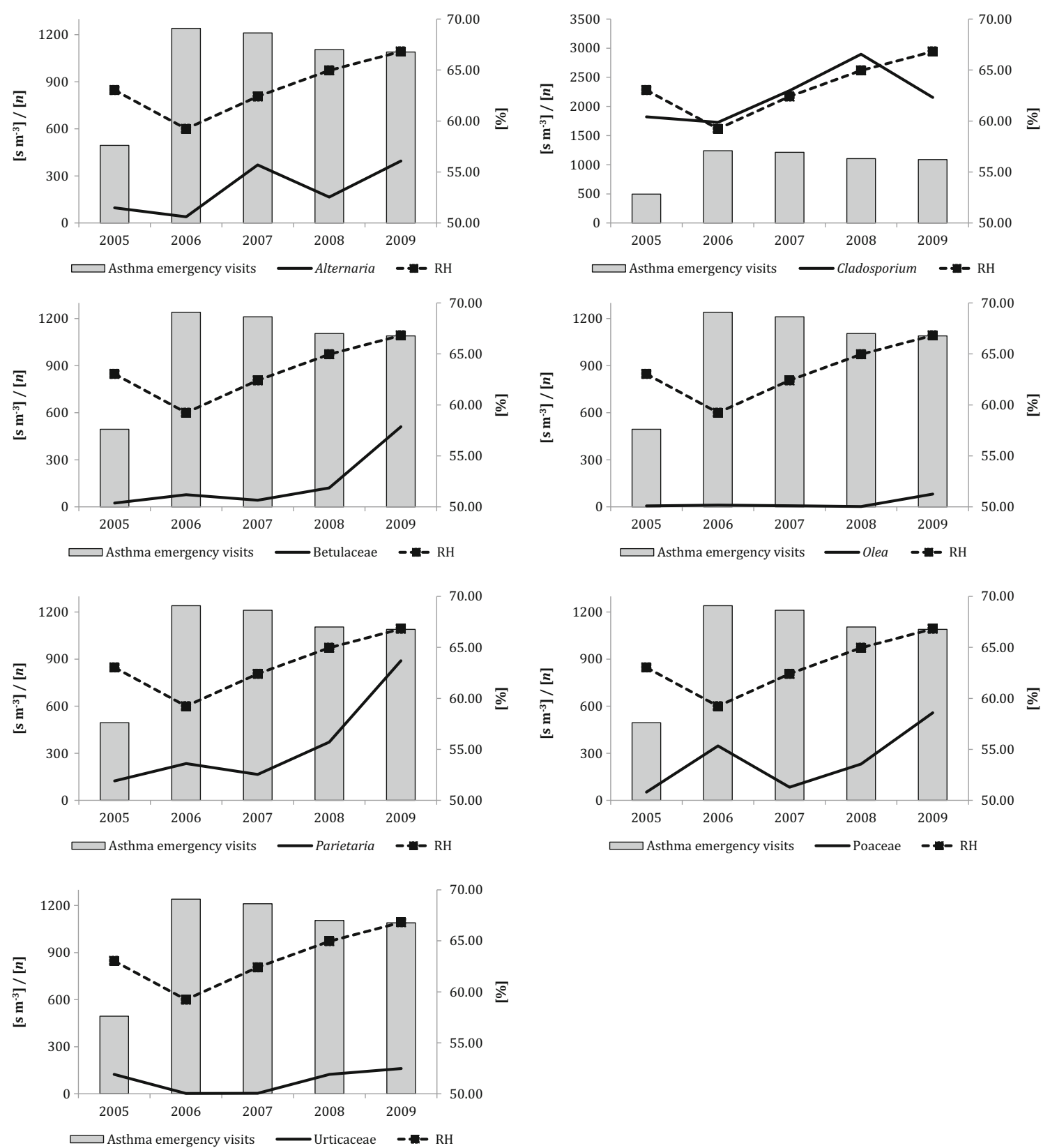

Fig. 5 Associations between examined fungal spores (Seasonal Fungal Indices) and pollen grains (Seasonal Pollen Indices), annual mean relative humidity (RH) and number of asthma-related emergency visits recorded at Funchal, Madeira Island (Jun 2005-Dec 2009)

An overview of the weather changes was given in Fig. S2 and Tables 4 and 6 . Air temperature and relative humidity are the major factors that govern fungal spore production and their release mechanisms; for instance, the optimal temperature for Alternaria brassicae and A. brassicicola sporulation require $18-24^{\circ} \mathrm{C}$ and $20-30{ }^{\circ} \mathrm{C}$, respectively, and $87-92 \%$ of relative humidity (Humperson-Jones and Phelps 1989). Although these conditions matched, the Alternaria spore counts were rarely observed in the air of Funchal (Table 3). However, the impact of climate change on bioaerosol concentrations is not yet fully understood; some authors suggest a decline in future spore concentration and hence a decreasing number of emergency visits caused by asthma (Damialis et al. 2015; Sadyś et al. 2015b). Graphs presented in Fig. S2 uniformly showed a gradual increase in mean air temperature, relative humidity and precipitation at Madeira Island.

Although the climate change must be partly responsible for low bioaerosol concentrations in the air of Funchal, it does not entirely explain the observed phenomenon. Noteworthy is the fact that major wind directions observed throughout the year were coming from the SW and SE directions (Fig. S2). The air masses blowing from the south originated over the Atlantic 

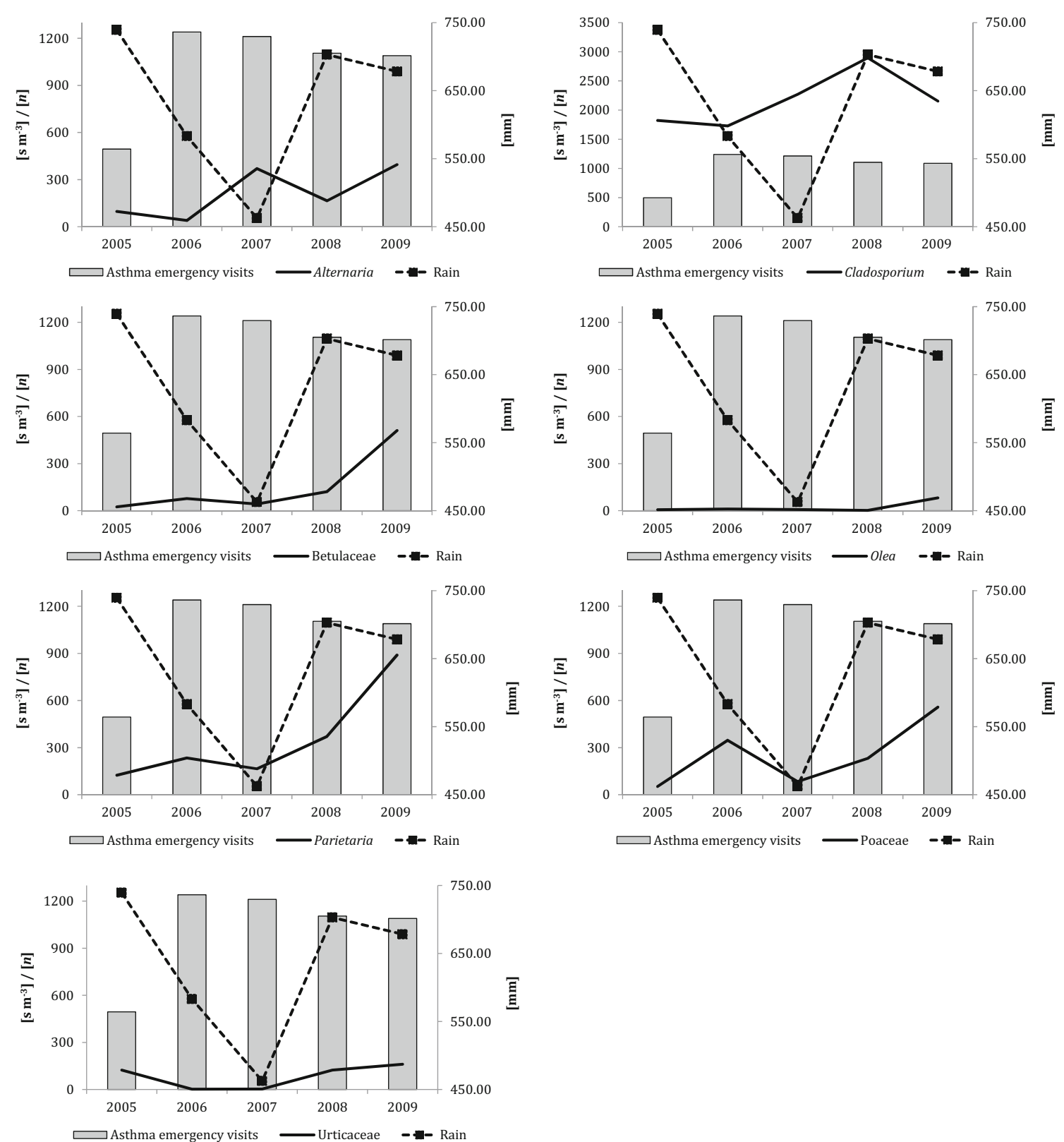

Fig. 6 Associations between the examined fungal spores (Seasonal Fungal Indices) and pollen grains (Seasonal Pollen Indices), annual precipitation and number of asthma-related emergency visits recorded at Funchal, Madeira Island (Jun. 2005-Dec. 2009)

Table 6 Results of Spearman's rank correlation test between daily emergency visits and bioaerosol concentrations measured at Funchal, Madeira (Jun 2005-Dec 2009)

\begin{tabular}{ll}
\hline Bioaerosol & Emergency visits \\
\hline Alternaria & 0.014 \\
Cladosporium & -0.047 \\
Betulaceae & -0.029 \\
Olea & -0.011 \\
Poaceae & -0.041 \\
Urticaceae & -0.036 \\
\hline
\end{tabular}

*Statistical significance at $p \leq 0.05$
Ocean and, therefore, must be free from any biological material, as suggested by Urbano et al. (2011). A previous survey performed by McGregor et al. (1999) revealed that cold and maritime air masses could be used as a predictor for a decrease in the number of emergency visits related to the respiratory tract infections since they were associated with a decline in air pollution. In contrast, the air masses arriving from the NNE bearing in 2009, although they originated on the African continent, they did not contribute significantly towards the pollen and spore counts trapped in Funchal due to the lack of suitable sources (Table 2, Fig. S1). 
In the end, a very low numbers of the pollen grain and fungal spore concentrations with allergenic properties recorded in Funchal from spring to autumn suggest that Madeira Island can be considered as a safe touristic destination for allergic sufferers.

Acknowledgments We would like to thank the Unit of Management of Patients and Statistic of Hospital Central of Funchal, the Portuguese Society of Allergology and Clinical Immunology (SPAIC) and the Meteorological Observatory of Funchal for their help and support in the aerobiological study.

\section{References}

Abu-Dieyeh MH, Barham R, Abu-Elteen K, Al-Rashidi R, Shaheen I (2010) Seasonal variation of fungal spore populations in the atmosphere of Zarqa area, Jordan. Aerobiologia 26:263-276

Aira MJ, Rodríguez-Rajo FJ, Jato V (2008) 47 annual records of allergenic fungi spore: predictive models from the NW Iberian Peninsula. Ann Agric Environ Med 15:91-98

Aradóttir AL, Robertson A, Moore E (1997) Circular statistical analysis of birch colonization and the directional growth response of birch and black cottonwood in south Iceland. Agric For Meteorol 84:179-186

Asthma GIf (2010) Global strategy for asthma prevention. National Institutes of Health, National Heart, Lung, and Blood Institute, Bethesda

Ataygul E, Celenk S, Canitez Y, Bicakci A, Malyer H, Sapan N (2007) Allergenic fungal spore concentrations in the atmosphere of Bursa, Turkey. J Biol Environ Sci 1:73-79

Atkinson RW, Strachan DP, Anderson HR, Hajat S, Emberlin J (2006) Temporal associations between daily counts of fungal spores and asthma exacerbations. Occup Environ Med 63:580-590

Belmonte J, Puigdemunt R, Cuevas E, Alonso S, González R, Poza P et al (2008) Eolo-PAT project: aerobiology and respiratory allergies in Santa Cruz de Tenerife since 2004. Allergy 63:58-611

Brito FF, Gimeno PM, Martínez C, Tobías A, Suárez L, Guerra F et al (2007) Air pollution and seasonal asthma during the pollen season. A cohort study in Puertollano and Ciudad Real (Spain). Allergy 62: $1152-1157$

Brito FF, Mur Gimeno P, Carnés J, Fernández-Caldas E, Lara P, Alonso AM et al (2010) Grass pollen, aeroallergens, and clinical symptoms in Ciudad Real, Spain. J Investig Allergol Clin Immunol 20:295-302

Brito FF, Gimeno PM, Carnés J, Martín R, Fernández-Caldas E, Lara P et al (2011) Olea europaea pollen counts and aeroallergen levels predict clinical symptoms in patients allergic to olive pollen. Ann Allergy Asthma Immunol 106:146-152

Caillaud D, Martin S, Segala C, Besancenot JP, Clot B, Thibaudon M (2014) Effects of airborne birch pollen levels on clinical symptoms of seasonal allergic rhinoconjunctivitis. Int Arch Allergy Immunol $163: 43-50$

Camacho IC (2015) Airborne pollen in Funchal city, (Madeira Island, Portugal) - first pollinic calendar and allergic risk assessment. Ann Agric Environ Med 22(4):608-613

D'Amato G (2007) Pollen allergy in Europe. The UCB Institute of Allergy 1-12

D'Amato G, Liccardi G (1994) Pollen related allergy in the European Mediterranean area. Clin Exp Allergy 24:210-219

D’Amato G, Cecchi L, Bonini S, Nunes C, Annesi-Maesano I, Behrendt $\mathrm{H}$ et al (2007) Allergenic pollen and pollen allergy in Europe. Allergy 62:976-990
D'Amato G, Holgate ST, Pawankar R, Ledford DK, Cecchi L, Al-Ahmad $\mathrm{M}$ et al (2015) Meteorological conditions, climate change, new emerging factors, and asthma and related allergic disorders. A statement of the world allergy organization. World Allergy Organ J 8:25

Dales RE, Cakmak S, Burnett RT, Judek S, Coates F (2000) Influence of ambient fungal spores on emergency visits for asthma to a regional children's hospital. Am J Respir Crit Care Med 162:2087-2090

Damialis A, Mohammad AB, Halley JM, Gange AC (2015) Fungi in a changing world: growth rates will be elevated, but spore production may decrease in future climates. Int J Biometeorol 59:1157-1167

Dixit A, Lewis W, Baty J, Crozier W, Wedner J (2000) Deuteromycete aerobiology and skin-reactivity patterns. Grana 39:209-218

EC (2003) Global land cover 2000 database. In: Joint Research Centre $\mathrm{EC}$, editor, Ispra

Emberlin J, Detandt M, Gehrig R, Jaeger S, Nolard N, Rantio-Lehtimäki A (2002) Responses in the start of Betula (birch) pollen seasons to recent changes in spring temperatures across Europe. Int $\mathrm{J}$ Biometeorol 46:159-170

Fisher NI (1993) Statistical analysis of circular data. University Press, Cambridge

Florido JF, Delgado PG, de San Pedro BS, Quiralte J, de Saavedra JM, Peralta V et al (1999) High levels of Olea europaea pollen and relation with clinical findings. Int Arch Allergy Immunol 119: $133-137$

Frankland AW, Davies RR (1965) Allergy to mold spores in England. Poumon Coeur 21:11-31

Galán C, Tobías A, Banegas JR, Aránguez E (2003) Short-term effects of air pollution on daily asthma emergency room admissions. Eur Respir J 22:802-808

Galán C, Cariñanos P, Alcázar P, Dominguez E (2007) Spanish aerobiology network (REA): management and quality manual. Universidad de Córdoba, Córdoba

Ghosh D, Chakraborty P, Gupta J, Biwas A, Roy I, Das S et al (2012) Associations between pollen counts, pollutants, and asthma-related hospital admissions in a high-density Indian metropolis. J Asthma 49:792-799

Gioulekas D, Damialis A, Papakosta D, Spieksma F, Giouleka P, Patakas D (2004) Allergenic fungi spore records (15 years) and sensitization in patients with respiratory allergy in Thessaloniki-Greece. J Invest Allerg Clin 14:225-231

Global Asthma Network. The global asthma report 2014. 2014 [cited; Available from: http://www.globalasthmareport.org/resources/ Global_Asthma_Report_2014.pdf

Gonianakis M, Neonakis I, Darivianaki E, Gonianakis I, Bouros D, Kontou-Fili K (2005) Airborne Ascomycotina on the island of Crete: seasonal patterns based on an 8-year volumetric survey. Aerobiologia 21:69-74

Héguy L, Garneau M, Goldberg MS, Raphoz M, Guay F, Valois M-F (2008) Associations between grass and weed pollen and emergency department visits for asthma among children in Montreal. Environ Res 106:203-211

Hodder R, Lougheed MD, Rowe BH, Fitzgerald JM, Kaplan AG, McIvor RA (2010) Management of acute asthma in adults in the emergency department: nonventilatory management. CMAJ 182:E55-E67

Humperson-Jones FM, Phelps K (1989) Climatic factors influencing spore production in Alternaria brassicae and Alternaria brassicicola. Ann Appl Biol 114:449-458

Kasprzyk I (2008) Non-native Ambrosia pollen in the atmosphere of Rzeszow (SE Poland). Evaluation of the effect of weather conditions on daily concentrations and starting dates of the pollen season. Int $\mathrm{J}$ Biometeorol 52:341-351

Kiotseridis H, Cilio CM, Bjermer L, Tunsäter A, Jacobsson H, Dahl Å (2013) Grass pollen allergy in children and adolescents symptoms, health related quality of life and the value of pollen prognosis. Clin Transl Allergy 3:19 
Knox RB, Taylor P, Smith P, Hough T, Ong EK, Suphioglu C et al (1993) Pollen allergens, botanical aspects. In: Kraft D, Sehon A (eds) Molecular biology and immunology of allergens. CRC Press, Boca Raton, pp 31-34

Koskela HO (2007) Cold air-provoked respiratory symptoms: the mechanisms and management. Int J Circumpolar Health 66(2):91-100

Leblanc A, Silva R, Dias de Castro E (2013) Asthmatic admissions in a central hospital emergency department. Rev Port Imunoalergologia $21: 275-282$

Lee CC, Sheridan SC, Lin S (2012) Relating weather types to asthma-related hospital admissions in New York State. EcoHealth 9:427-439

León-Ruiz E, Alcázar P, Domínguez-Vilches E, Galán C (2010) Study of Poaceae phenology in a Mediterranean climate. Which species contribute most to airborne pollen counts? Aerobiologia 27:37-50

Loureiro G, Blanco B, São Braz M, Pereira C (2003) Reactividade cruzada a aeroalergénios numa população alérgica da Cova da Beira. Rev Port Imunoalergologia 11:107-116

Makra L, Puskás J, Matyasovszky I, Csépe Z, Lelovics E, Bálint B, Tusnády G (2015) Weather elements, chemical air pollutants and airborne pollen influencing asthma emergency room visits in Szeged, Hungary: performance of two objective weather classifications. Int J Biometeorol 59(9):1269-1289

Masoli M, Fabian D, Holt S, Beasley R (2004) The global burden of asthma: executive summary of the GINA Dissemination Committee Report. Allergy 59:469-478

May L, Carim M, Yadav K (2011) Adult asthma exacerbations and environmental triggers; a retrospective review of ED visits using an electronic medical record. Am J Emerg Med 29:1074-1082

McGregor G, Walters S, Wordley J (1999) Daily hospital respiratory admissions and winter air-mass types, Birmingham UK. Int $\mathrm{J}$ Biometeorol 43:21-30

Negrini AC, Voltolini S, Troise C, Arobba D (1992) Comparison between Urticaceae (Parietaria) pollen count and hay fever symptoms: assessment of a «threshold-value». Aerobiologia 8:325-329

Newson R, Strachan D, Corden J, Millington W (2000) Fungal and other spore counts as predictors of admissions for asthma in the Trent region. Occup Environ Med 57:786-792

Nilsson S, Persson S (1981) Tree pollen spectra in the Stockholm region (Sweden), 1973-1980. Grana 20:179-182

Nunes C, Ladeira S (2012) Long-term efficacy of specific immunotherapy in rhino-conjunctivitis to pollens. Rev Port Imunoalergologia 20: 253-261

Oliveira P, Pereira PT (2008) Who values what in a tourism destination? The case of Madeira Island. Tour Econ 14:155-168

Puc M, Bosiacka B (2011) Effects of meteorological factors and air pollution on urban pollen concentrations. Pol J Environ Stud 20: 611-618

Quintal R (2007) Quintas, Parques e Jardins do Funchal - Estudo fitogeográfico. Lisboa: Esfera do Caos Editores

Ranta H, Pessi A-M (2006) Pollen bulletin summary 2005. Finn Pollen Bull 30:1-12

Rapiejko P, Stankiewicz W, Szczygielski K, Jurkiewicz D (2007) Threshold pollen count necessary to evoke allergic symptoms. Otolaryngol Pol 61:591-594

Ribeiro H, Oliveira M, Ribeiro N, Cruz A, Ferreira A, Machado H, Reis A, Abreu I (2009) Pollen allergenic potential nature of some trees species: a multidisciplinary approach using aerobiological, immunochemical and hospital admissions data. Environ Res 109(3):328-333

Rivas-Martínez S (2001) Bioclimatic map of Europe - thermotypes. University of Léon, Léon

Rodríguez-Rajo FJ, Astray G, Ferreiro-Lage JA, Aira MJ, Jato-Rodríguez MV, Mejuto JC (2010) Evaluation of atmospheric Poaceae pollen concentration using a neural network applied to a coastal Atlantic climate region. Neural Netw 23:419-425

Rosado-Pinto J, Gaspar A, Morais-Almeida M (2006) Épidémiologie de l'asthme et des allergies dans les pays de langue portugaise. Revue Française d'allergologie et d'immunologie Clinique 46:305-308

Rosas I, McCartney HA, Payne RW, Calderón C, Lacey J, Chapela R et al (1998) Analysis of the relationships between environmental factors (aeroallergens, air pollution, ad weather) and asthma emergency to a hospital in Mexico City. Allergy 53:394-401

Royé D, Taboada JJ, Martín A, Lorenzo MN (2015) Winter circulation weather types and hospital admissions for respiratory diseases in Galicia, Spain. Int J Biometeorol. doi:10.1007/s00484-015-1047-1

Ruffoni G, Passalacqua G, Ricciardolo F, Furgani A, Corrado Negrini A, De Amici M et al (2013) A 10-year survey on asthma exacerbations: relationships among emergency medicine calls, pollens, weather, and air pollution. Rev Fr Allergol 53:569-575

Sabariego S, Díez A, Gutiérrez M (2007) Monitoring of airborne fungi in Madrid (Spain). Acta Bot Croat 66:117-126

Sadyś M, Kennedy R, Skjoth CA (2015a) An analysis of local wind and air mass directions and their impact on Cladosporium distribution using HYSPLIT and circular statistics. Fungal Ecol 18:56-66

Sadyś M, Kennedy R, West JS (2015b) Potential impact of climate change on fungal distributions: analysis of 2 years of contrasting weather in the UK. Aerobiologia

Santos FD, Valente MA, Miranda PMA, Aguiar A, Azevedo EB, Tomé AR et al (2004) Climate change scenarios in the Azores and Madeira islands. WRR 16:473-491

Singh AB, Mathur C (2012) An aerobiological perspective in allergy and asthma. Asia Pac Allergy 2:210-222

Sousa L, Camacho I, Grinn-Gofroń A, Camacho R (2015) Monitoring of anamorphic fungal spores in Madeira region (Portugal), 2003-2008. Aerobiologia 31:1-13

To T, Stanojevic S, Moores G, Gershon AS, Bateman ED, Cruz AA et al (2012) Global asthma prevalence in adults: findings from the crosssectional world health survey. BMC Public Health 12:1-8

Tormo-Molina R, Gonzalo-Garijo MA, Silva-Palacios I, MuñozRodríguez AF (2010) General trends in airborne pollen production and pollination periods at a Mediterranean site (Badajoz, Southwest Spain). J Investig Allergol Clin Immunol 20:567-574

Tosunoglu A, Bicakci A (2015) Seasonal and intradiurnal variation of airborne pollen concentrations in Bodrum, SW Turkey. Environ Monit Assess 187:167

Urbano R, Palenik B, Gaston CJ, Prather KA (2011) Detection and phylogenetic analysis of coastal bioaerosols using culture dependent and independent techniques. Biogeosciences 8:301-309

Veriankaite L, Siljamo P, Sofiev M, Šaulienė I, Kukkonen J (2010) Modelling analysis of source regions of long-range transported birch pollen that influences allergenic seasons in Lithuania. Aerobiologia $26: 47-62$

WHO. Asthma, http://www.who.int/topics/asthma/en/, 2015 